Gynecologic and

Obstetric Investigation
Gynecol Obstet Invest 2012;74:249-260

DOI: $\underline{10.1159 / 000342997}$
Received: January 25, 2012

Accepted after revision: August 23, 2012

Published online: October 25, 2012

\title{
Early Abdominal Ectopic Pregnancies: A Systematic Review of the Literature
}

\author{
Aaron Poole $^{\mathrm{a}}$ David Haas ${ }^{\mathrm{b}}$ Everett F. Magann ${ }^{\mathrm{c}}$ \\ Departments of Obstetrics and Gynecology, ${ }^{a}$ Naval Hospital Lemoore, Lemoore, Calif., ${ }^{b}$ Medical, Indiana University \\ School of Medicine, Indianapolis, Ind., and 'University of Arkansas for the Medical Sciences, Little Rock, Ark., USA
}

\section{Key Words}

Abdominal ectopic pregnancy - Abdominal pregnancies, literature review $\cdot$ Ectopic pregnancies $\cdot$ Ectopic pregnancy outcomes - Maternal mortality - Pathophysiology •

Pregnancy outcomes

\begin{abstract}
Objective: To define abdominal ectopic pregnancy outcomes by both location and treatment. Methods: Literature review of abdominal pregnancies from 1965 to August of 2009. Ectopic pregnancy exclusions were interstitial, tubal, cervical, ovarian, or those beyond 20 weeks at diagnosis/ treatment. Results: There were 511 cases identified with 225 meeting the inclusion criteria. There were 7 maternal deaths (3.0\%) with 18 (8\%) of the early abdominal ectopic pregnancies occurring with an intrauterine device in place. Mean gestational age at the time of treatment was 10 weeks 0 days and mean maternal age was 29.7 years. The average blood loss associated with treatment was $1,450 \mathrm{ml}$. The top three sites of early abdominal ectopic pregnancies were pouches around the uterus (24.3\%), serosal surface of the uterus and tubes $(23.9 \%)$, and multiple sites (12.8\%). Primary surgical management was performed in 208 cases (87.8\%). Nonsurgical adjuvant or primary therapy included intramuscular methotrexate, intralesional methotrexate, intracardiac $\mathrm{KCl}$, and artery embolization. Conclusion: Abdominal pregnan-
\end{abstract}

cies should be considered in all patients until an intrauterine location can be confirmed. Understanding treatment options by pregnancy location may be helpful in the management of this potentially life-threatening condition.

Copyright $\odot 2012$ S. Karger AG, Basel

\section{Introduction}

Abdominal pregnancies have been defined as serosal pregnancies occurring within the peritoneal cavity but excluding those pregnancies that are tubal, ovarian, intraligamentous, or the result of a secondary implantation of primary tubal implantation [1]. The criteria used to diagnose a primary abdominal pregnancy were initially described by Studdiford [1] in 1944. He stated the following criteria had to be met to classify a pregnancy as abdominal: (1) normal tubes and ovaries, (2) no evidence of uteroperitoneal fistula, (3) pregnancy related solely to the peritoneal surface, and (4) no evidence of secondary implantation following initial primary tubal nidation.

The views expressed in this article are the views of the author and do not necessarily reflect the official policy or position of the Department of the Navy, Department of Defense, or the US Government.

\section{KARGER}

Fax +41613061234

E-Mail karger@karger.ch

www.karger.com
(C) 2012 S. Karger AG, Basel

$0378-7346 / 12 / 0744-0249 \$ 38.00 / 0$

Accessible online at:

www.karger.com/goi
Everett F. Magann, MD

Department of OB/GYN, University of Arkansas for the Medical Sciences 4301 W. Markam St., Slot \#518

Little Rock, AR 72205 (USA)

E-Mail efmagann@uams.edu 
In a review of abdominal pregnancies from 1979 to 1982 , abdominal pregnancies were observed to occur in 10.9 per 100,000 pregnancies and in 9.2 per 1,000 ectopic pregnancies [2]. Of the 11 maternal deaths reviewed, 6 (54.5\%) occurred prior to 20 weeks with an overall maternal mortality rate of 5.1 per 1,000 pregnancies. The maternal mortality rate was 7.7 times higher than that observed in tubal ectopic pregnancies and 90 times higher than in an intrauterine pregnancy.

One of the factors contributing to the high maternal mortality rate may be that abdominal ectopic pregnancies are commonly misdiagnosed. In one large series, only 1 out of 9 women who reached the hospital alive had a correct preoperative diagnosis [2]. Allibone et al. [3] set forth the following ultrasonic criteria for the diagnosis of abdominal pregnancy: (1) fetus outside the uterus, (2) failure to see a uterine wall between the fetus and the urinary bladder, (3) close approximation of fetal parts and maternal abdominal wall, (4) eccentric position/attitude of fetus, (5) placenta outside the uterine cavity, and (6) visualization of the placenta immediately adjacent to the fetal chest and head with no amniotic fluid. Four common pitfalls in diagnosis include: anterior uterine leiomyoma, retroflexed uterus, false-negative diagnosis as intrauterine pregnancy, and false-positive diagnosis with bicornuate uterus [4]. Due to its rarity, only case reports or small case series exist in the literature. With so little information on the diagnosis and treatment of abdominal ectopic pregnancies, management has included surgical therapy (laparotomy and laparoscopy), medical therapy (intramuscular or intralesional methotrexate and/or intracardiac $\mathrm{KCl}$ ) or a combination of medical and surgical management. The purpose of this review was to evaluate the literature over the past 45 years for all reports involving early abdominal pregnancies (prior to 20 weeks' gestational age) and evaluate maternal demographics, medical and surgical treatments, and maternal outcomes.

\section{Methods}

A literature search was undertaken using the search engines PubMed (includes MEDLINE), CINAHL Plus, Healthsource, Nursing/Acad, and Web of Science between 1965 to August 2009. This study was limited to human studies in English. The search terms used were 'abdominal pregnancy' OR 'splenic pregnancy' OR 'abdominal ectopic pregnancy' OR 'hepatic pregnancy' OR 'omental pregnancy' OR 'primary peritoneal pregnancy'.

There were 538 abstracts identified. The abstracts of all the articles were read and the full articles of any abstract that involved an abdominal pregnancy less than 20 weeks of gestation were reviewed. The bibliographies of all articles with an early abdominal pregnancy were screened for any additional articles. The following abstracts were excluded based on: gestational age above 20 weeks $(n=276)$, review article only $(n=30)$, lithopedian $(n=26)$, not able to obtain $(n=20)$, other $(n=18)$, interstitial/tubal/ovarian $(n=10)$, rudimentary horn $(n=5)$, cesarean scar $(n=5)$, and insufficient information $(n=20)$. The remaining cases included 146 reports with cross-reference generating an additional 32 reports for a total of 179 articles. Of these, 23 involved more than 1 case for a total of 225 cases that form the basis of this review (fig. 1)

Data extracted included the number of women within the article meeting the inclusion criteria, the site of the ectopic pregnancy, the surgical and/or medical management, blood loss, pathology records and maternal morbidity/mortality. Clinical variables such as maternal age, parity, quantitative $\beta$-human chorionic gonadotropin (HCG) levels, and gestational age were also recorded if available. Descriptive statistics are provided. Comparisons were made between clinical variables, such as the presence of an intrauterine device (IUD), and outcomes. Continuous variables were compared with t tests or ANOVAs and discreet variables compared with $\chi^{2}$ testing. A logistic regression model was constructed to assess for the clinical predictors of successful first treatment for women who received medical treatment initially.

\section{Results}

Of the 225 abdominal pregnancies meeting the criteria, there were 7 maternal deaths for a maternal death rate of $3 \%$. IUDs were present in $18(8 \%)$ of the abdominal ectopic pregnancies. The mean maternal age was $29.7 \pm 5.8$ years with a range of 13-46 years and varied by location with the youngest women more likely to have the abdominal ectopic on the abdominal wall and the oldest having ectopics on the abdominal blood vessels (fig. 2). The average parity was 1.3 (range $0-10$ ). The mean gestational age at the time of the diagnosis was 10 weeks 0 days \pm 4 weeks 3 days and ranged by location from 7 weeks 0 days for the spleen to 13 weeks 4 days for multiple, 6 weeks for the diaphragm to 16 weeks 4 days for maternal abdominal blood vessels (fig. 3). Fetal cardiac activity was observed in $40(18 \%)$ of the cases. Blood loss was documented or a hemoperitoneum was described in 108 (48\%) of the women. The average blood loss described was $1,450 \mathrm{ml}$ with a range of 50-7,500 $\mathrm{ml}$ with $56(25 \%)$ of the women receiving a blood transfusion (fig. 4).

\section{Locations of the Abdominal Pregnancies}

Abdominal ectopic pregnancies were divided into the following categories in order from most reported to least: pouches around uterus, uterus-adnexa, multiple abdominal organs, omental, bowel-appendix, hepatic, splenic, retroperitoneal, abdominal wall and others (table 1). 
Fig. 1. Literature search for abdominal

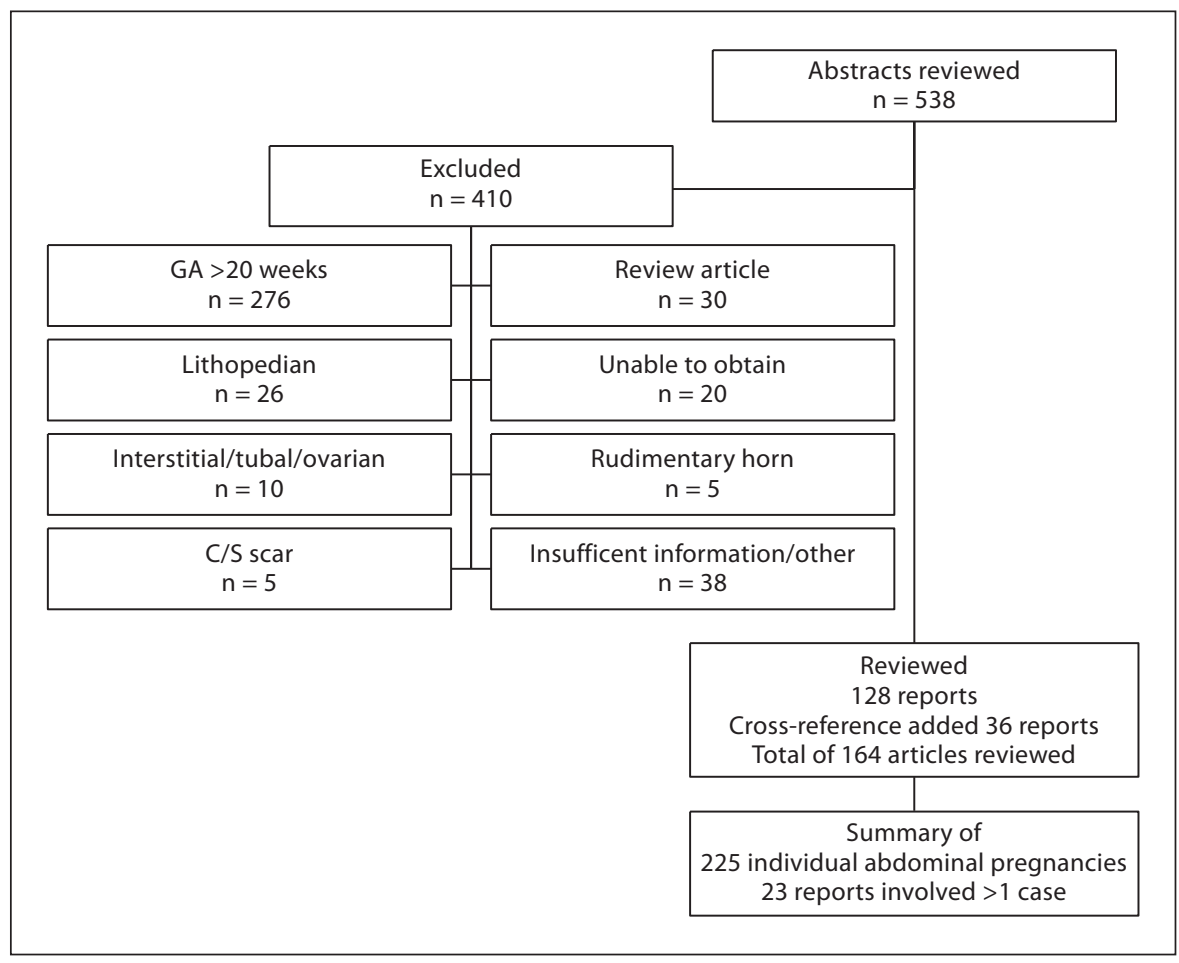
pregnancy. $\mathrm{C} / \mathrm{S}=$ Cesarean section.

Pouches Surrounding Uterus

This was the most frequent location for abdominal pregnancies with 55 cases identified [5-48]. The average age of the patient was 31 with a gestational age of 9 weeks for initial treatment and parity of 1.6.

The pregnancies were primarily located posteriorly in the pouch of Douglas $46 / 55$ (87\%) versus anteriorly $9 / 55$ $(16 \%)$. Both the anterior and posterior implantations were generally treated by exploratory laparotomy, but 12 cases were treated laparoscopically $[10,14,17,18,29,31,37,42$, $45]$. One patient had a vaginal hysterectomy 2 months prior to surgery [6]. IUDs were present in 6 patients [20, $22,24,28,36]$.

Eight patients were treated with medical therapy as either primary treatment or adjuvants $[12,14,19,26,38$, 46-48]. There were 3 cases of successful treatment with methotrexate of abdominal pregnancies which were located in the pouch of Douglas. The first case had an HCG of 210, no fetal cardiac activity, and treated with one dose of intramuscular (IM) methotrexate $50 \mathrm{mg} / \mathrm{m}^{2}$ [19]. The second case had an HCG of 2,619, no fetal cardiac activity, and treated with methotrexate $50 \mathrm{mg} / \mathrm{m}^{2} \mathrm{IM}$ on days $1,3,5$ and 7 combined with folinic acid $0.1 \mathrm{mg} / \mathrm{kg}$ on days $2,4,6$, and 8 [47]. The final case had an HCG of 28,810, fetal cardiac activity, and treated with methotrexate 50 $\mathrm{mg} / \mathrm{m}^{2} \mathrm{IM}$ and $50 \mathrm{mg}$ intralesional methotrexate [12].

Early Abdominal Ectopic Pregnancies: A Systematic Review of the Literature
There were 3 cases of abdominal pregnancy on the serosal surface of the bladder $[11,14,46]$. One of the cases was initially treated with a $\mathrm{KCl}$ injection, subsequently hemorrhaged requiring 30 units of blood, was treated with embolization of the left internal iliac artery, and 14 days later with embolization of the left lumbar artery [14]. Another case was initially treated with methotrexate, subsequently developed an acute abdomen, and had a partial resection of the ectopic followed by a second dose of methotrexate [46]. The third case underwent a laparotomy with resection of the ectopic with a blood loss of 600 [11].

There were no maternal deaths and fetal cardiac activity was present in 8 of 55 cases.

\section{Serosa of the Uterus and Adnexa}

There were 54 cases of pregnancies implanted on the uterus or adnexa $[2,24,28,34,42,44,49-75]$. The average maternal age was 29.6 years, with gestational age of 11 weeks 2 days and parity of 0.8 . The average blood loss was $1,560 \mathrm{ml}$. Six patients with implantation on the uterus required hysterectomy $[34,53,74]$. Uterine artery or internal iliac artery embolization was used in 1 patient preoperatively [52] and 1 patient postoperatively [65]. None of these pregnancies underwent medical therapy (intramuscular or intralesional methotrexate and/or intracardiac $\mathrm{KCl})$. 


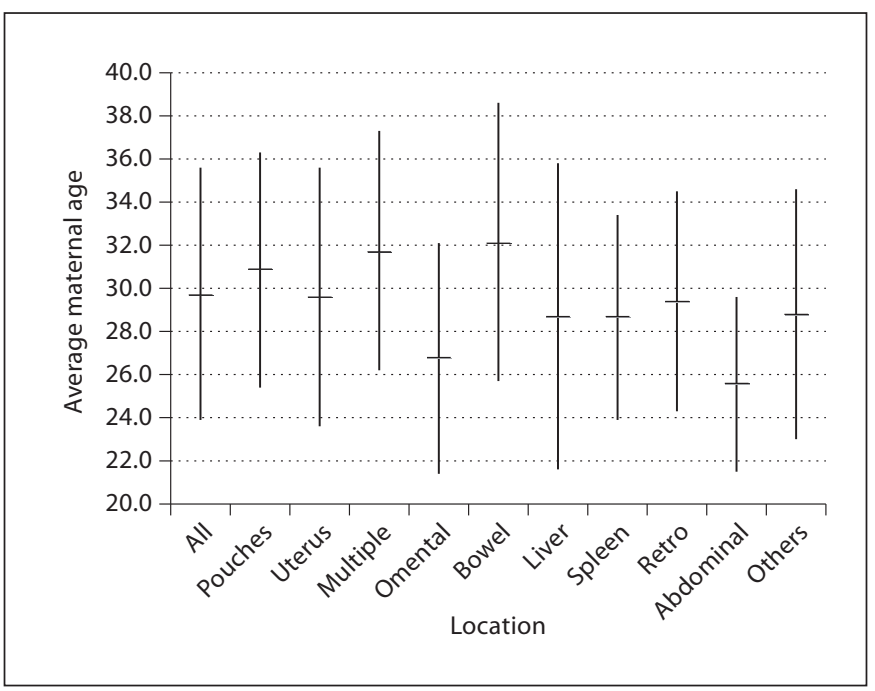

Fig. 2. Average maternal age with standard deviation by location. Retro $=$ Retroperitoneal.

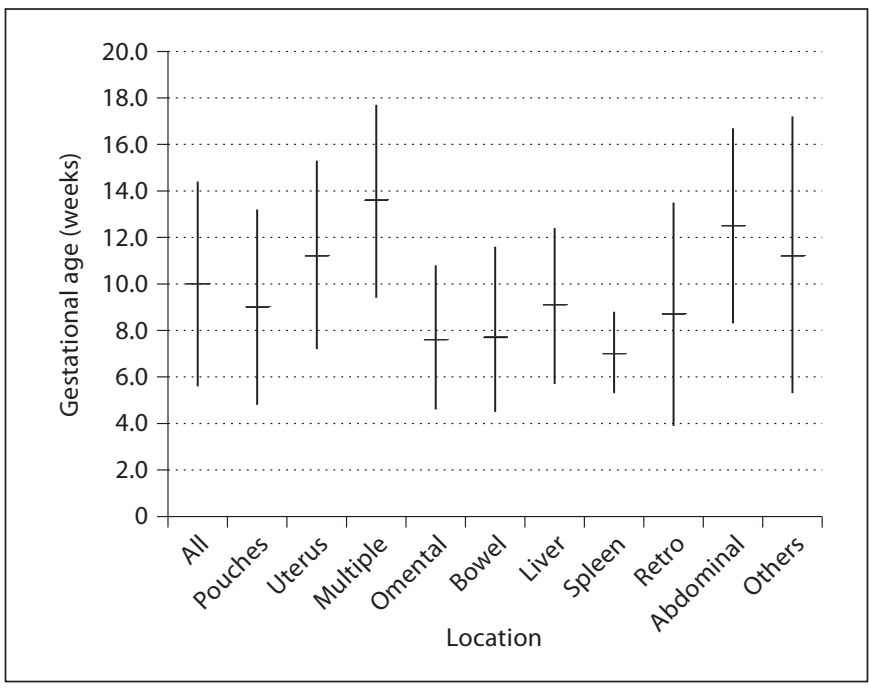

Fig. 3. Average gestational age with standard deviation (in weeks) by location. Retro = Retroperitoneal.

Table 1. Location and characteristics of the abdominal ectopic pregnancies

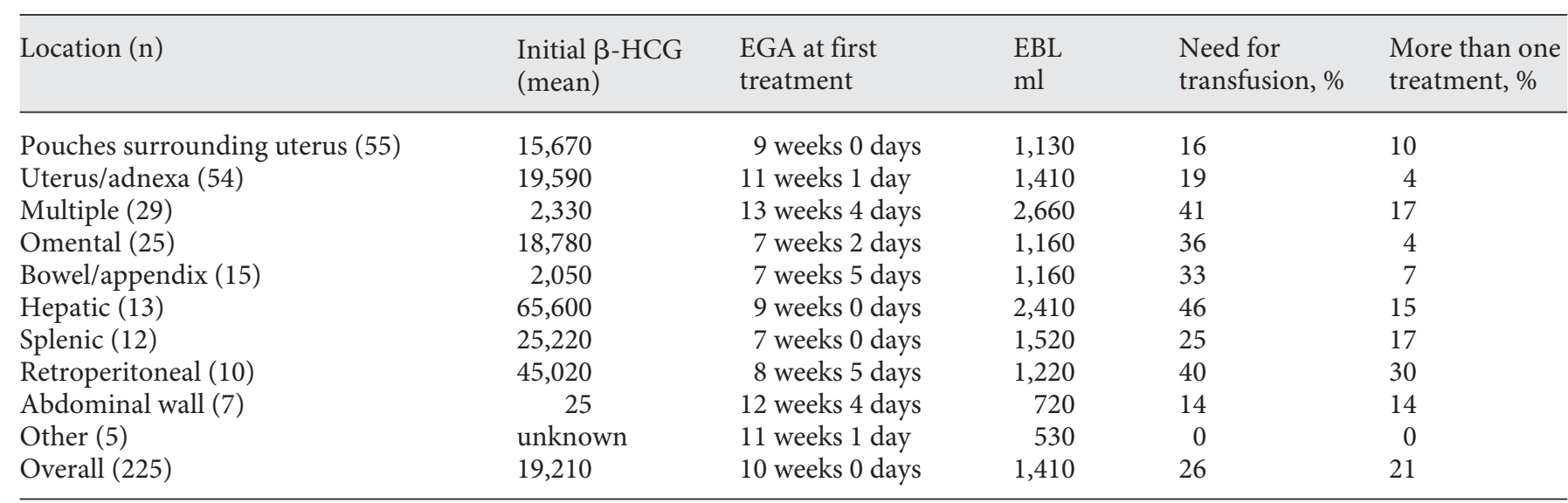

IUDs were present in 3 cases [24, 28, 62]. Prior hysterectomy had occurred in 2 patients $[66,75]$. The first case involved a patient diagnosed with an abdominal pregnancy at 14 weeks who was 12 weeks s/p TAH [75]. In the second case, the hysterectomy had taken place 12 months before [66]. Fetal cardiac activity was present in 4 cases $[51,54,67,70]$. Maternal death occurred in 5 of the 54 cases reported [2]. One patient was found dead at home while 3 patients died in the hospital 1-4 days after admission with presumed diagnoses of 'threatened abortion' or 'fetal death' prior to surgical intervention. The 1 patient who had surgery died after reoperation for continued bleeding.

\section{Multiple Abdominal Organs}

There were 29 cases of abdominal pregnancies that involved multiple abdominal organs $[25,33,34,44,55,57$, 76-92] with an average maternal age of 31.7 , parity of 2.2 , and gestational age of 13 weeks and 4 days. These women were operated on primarily and had an average blood loss of $2,650 \mathrm{ml}$ with 12 patients being transfused $[25,34,57$, $76,78,81,83,87,89,91,92]$. Four patients required a hysterectomy at the time of surgery $[34,81,83]$. Elevated maternal serum $\alpha$-fetoprotein was noted in 2 patients [89, 92]. The first patient [89] had a maternal serum AFP of 4.88 and the second patient [92] had a maternal serum AFP of 20 multiples of the median (MOM). In the latter 


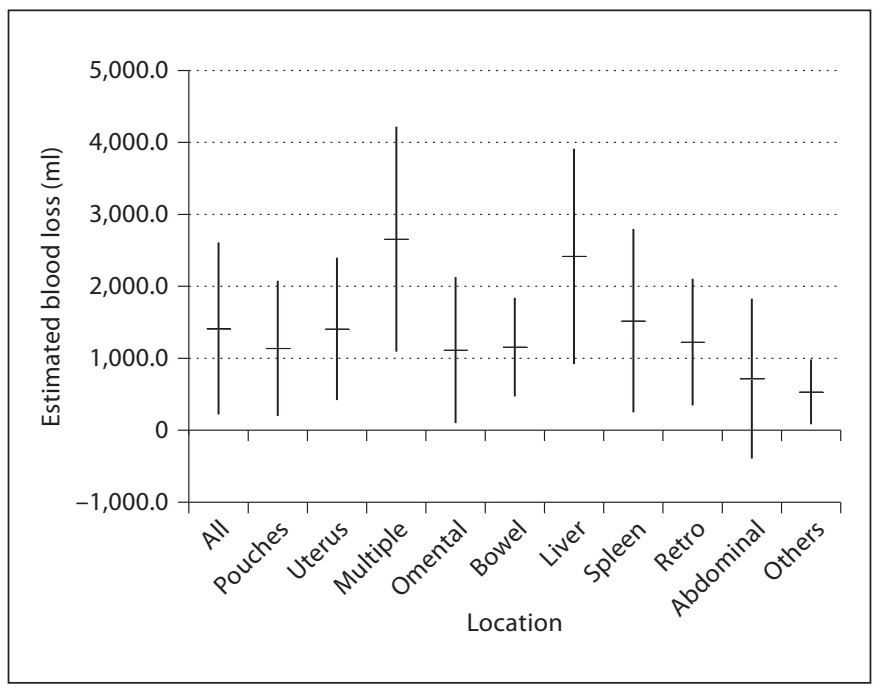

Fig. 4. Average estimated blood loss (in $\mathrm{ml}$ ) with standard deviation (in weeks) by location. Retro $=$ Retroperitoneal .

case, hepatoma and germ cell tumors were ruled out and AFP returned to normal 2 weeks after surgery.

One patient [87] at 16 weeks with fetal cardiac activity was treated with ultrasound-guided $\mathrm{KCl}$ intracardiac injection followed 1 week later by exploratory laparotomy and removal of products of conception. Two patients [80] at 6 weeks' gestational age (quantitative HCG of 3,760 and 4,300 ) had a diagnostic laparoscopy followed by one dose of IM methotrexate with complete resolution. Postoperative methotrexate $(10 \mathrm{mg} \mathrm{IM} \times 5$ days, then every other week $\times 6$ ) was given for a patient [83] with partial removal but placenta left in situ at 14 weeks' gestational age. There were no maternal deaths.

\section{Omentum}

There were 25 reports from 24 different references of an abdominal pregnancy being primarily implanted on the omentum [42, 93-115]. The patient's average age at initial presentation was 27 (range 13-36) with the average gestational age at diagnosis of 7 weeks and 2 days (range 4-16 weeks) and parity of 1.3. All of the ectopics were treated with at least a partial omentectomy and removal of adjacent ovaries and fallopian tubes in selected cases. Laparoscopy was used alone in 8 of 25 cases $[97,99,101$, $103,104,106,112,114](32 \%)$ with all but 1 case [112] occurring after year 2000. Omental ectopic pregnancies were more frequently treated by laparoscopy than abdominal ectopic pregnancies at all other locations. Of the 25 cases, 9 women $[93,98,100,102,109,111,113-115]$ re- ceived a blood transfusion (36\%) with an average blood loss of all cases of 1,160 ml (range minimal to 3,000 ml). All 25 patients presented with abdominal pain with 3 of the patients having pain in the epigastrium $[94,111,113]$. Additionally, 7 patients complained of nausea and/or vomiting [94-96, 100, 109, 113, 114].

None of the patients had an initial preoperative diagnosis of abdominal ectopic pregnancy. The location of the ectopic was determined intraoperatively when a tubal pregnancy was not found. Ultrasound was used in 20 of 25 patients and commonly showed no evidence of an intrauterine pregnancy, free fluid \pm an adnexal mass with the presumptive diagnosis of a ruptured tubal pregnancy. Culdocentesis was used in 6 patients [93, 96, 102, 103, 109] to assist in the diagnosis of a ruptured ectopic pregnancy. A delay in presentation to definitive treatment was noted in 8 patients $[94,95,98,101,103,107,111,114]$ with 2 of the patients having an initial negative laparoscopic examination $[95,114]$. After a diagnosis of a hemorrhagic corpus luteum in 1 patient [114], MRI was used after the HCG continued to rise following the negative laparoscopy and a dilation and curettage to identify the site of the abdominal ectopic pregnancy. The other patient was misdiagnosed at the time of laparoscopy and had a tubal abortion followed 2 days later by severe abdominal pain, hemoperitoneum, and subsequently underwent exploratory laparotomy [95]. There were no cases of maternal mortality. There were also no documented cases of fetal cardiac activity prior to the identification of the omental abdominal ectopic pregnancy.

\section{Bowel-Appendix}

The 15 abdominal pregnancies $[2,24,36,37,44,80$, $116,117,119-124]$ of the bowel and appendix were treated mainly by laparotomy except 2 cases successfully treated with laparoscopy alone $[37,116]$. The average maternal age was 32 with a parity of 1.46 and gestational age of 7 weeks 4 days. Five patients were transfused [117-119, 123, 124 ] with an average blood loss of $1,160 \mathrm{ml}$. Two patients had an IUD in place $[36,123]$.

Only 1 patient required a partial bowel resection [118] in an IVF pregnancy with patient history of bilateral salpingectomy complicated by a heterotopic pregnancy. A diagnostic laparoscopy followed by successful treatment of methotrexate was used in a patient at 7 weeks with a quantitative HCG of 1930 [80].

A 13-week abdominal pregnancy implanted on the sigmoid and vaginal cuff was found in a patient who was 11 weeks postvaginal hysterectomy and had failed preoperative embolization due to too many feeding vessels 
[117]. There were 3 cases of fetal cardiac activity $[116,117$, 122] and 1 case of maternal death [2].

\section{Liver}

There were 13 reports of the abdominal pregnancy being implanted on the liver with 11 of 13 cases $[125,126$, 128, 129, 131-137] involving the right lobe of the liver and 2 cases involving the caudate lobe [127] and near the falciform ligament [130]. The average maternal age was 29 with a gestational age of 9 weeks 0 days with a range of 4-14 weeks and parity of 3.7. Six of the 13 patients presented with either pain in the right upper quadrant or epigastrium.

The initial treatment of all but one of the ectopic pregnancies was surgical, resulting in an average blood loss of $2,400 \mathrm{ml}$ with 6 of the 13 receiving a transfusion at the time of the laparotomy. Staged surgery was needed in 1 case with packs left in place because of persistent bleeding, with removal the following day [127]. Another patient had an omental graft due to persistent bleeding from the placental attachment on the liver [131].

Three patients were treated medically either alone or as an adjunct to surgery $[125,134,136]$. In the case described by Delabrousse et al. [128], there was incomplete removal of the products of conception, followed by methotrexate given intramuscularly every $72 \mathrm{~h}$ for six doses due to persistently elevated HCG levels; treatment resulted in a complete recovery of the patient. Nichols et al. [134] determined at the time of laparotomy that the best treatment for the abdominal ectopic pregnancy was 20 mg of intralesional methotrexate because the embryo was adjacent to the porta hepatis. Shippey et al. [136], after a negative $\mathrm{D} \& \mathrm{C}$ and diagnostic laparoscopy, found the hepatic ectopic pregnancy on MRI confirmed the diagnosis with a right upper quadrant ultrasound at which time there was positive fetal cardiac activity and a quantitative HCG of 89,927 at a gestational age of 11 weeks. Under ultrasound guidance, $25 \mathrm{mg}$ of intracardiac methotrexate was given. However, 1 week later, fetal cardiac activity persisted. At that time, intracardiac $\mathrm{KCl}$ and IM methotrexate $50 \mathrm{mg} / \mathrm{m}^{2}$ was administered with a repeat dose of IM methotrexate 1 week later. No further interventions were required. There were no cases reported with a maternal mortality and 3 of the 13 cases presented with fetal cardiac activity $[128,129,137]$.

\section{Spleen}

There were 12 reports of the abdominal pregnancy being implanted on the spleen $[138,139,141-150]$ with an average maternal age of 28.7 and parity of 1.1. The average age at diagnosis was 7 weeks with the range being from 4 to 9 weeks and 3 days. Seven of the 12 patients presented with left shoulder pain and with next most common presenting complaint being an acute abdomen. The treatment for all was surgical with splenectomy via exploratory laparotomy except for 1 case [150] treated laparoscopically (also 1 case [140] after the endpoint of this review was treated laparoscopically but is not part of the 225 cases in this review). The 9 cases in which blood loss was reported averaged $1,520 \mathrm{ml}$, with 4 requiring a blood transfusion [141, 144, 148, 149].

There were no cases of maternal deaths and only 1 case with documented fetal cardiac activity in a patient who conceived with IVF [144]. Three patients had an IUD in place $[139,147,148]$. A delay in final treatment occurred in 3 patients [142, 144, 150], with 1 patient [142] having three exploratory laparotomies prior to undergoing an angiogram showing increased vascularity posterior to the spleen; this leads to a splenectomy with resolution of the ectopic pregnancy.

The gestational age at diagnosis occurred earlier for abdominal pregnancies of the spleen than the average gestational age for all sites combined. No patients in this series had an initial preoperative diagnosis of splenic pregnancy. The diagnoses were made intraoperatively when active bleeding was noted from the left upper quadrant.

\section{Retroperitoneal}

There were 10 cases of an abdominal pregnancy being implanted retroperitoneally [151-160]. The average age at diagnosis was 8 weeks 5 days with a range of 5-18 weeks with an average maternal age of 29.4 years and parity of 1.1. Eight of the cases were initially treated surgically with complete removal of the products of conception except for 1 successful case of intracardiac methotrexate $(50 \mathrm{mg})$ and $\mathrm{KCl}(2 \mathrm{mEq})$ with IM methotrexate $\left(50 \mathrm{mg} / \mathrm{m}^{2}\right)$ in a pregnancy implanted over the bifurcation of the left common iliac artery [158] and 1 case of failed medical management with two doses of methotrexate [156].

The first dose of methotrexate $\left(50 \mathrm{mg} / \mathrm{m}^{2} \mathrm{IM}\right)$ was given for a pregnancy of unknown location after a negative D\&C at $7+1$ weeks' gestational age (HCG 31,000) followed by a second dose after negative CT scan, MRI, and laparoscopy (HCG 43,000). At $9+6$ weeks' gestational age, the patient had the acute onset of upper abdominal pain in the right side. An ultrasound and MRI showed a fetal pole with no fetal cardiac activity. Due to its proximity to the aorta and inferior vena cava, and with falling HCG levels $(14,000)$, expectant management was chosen. However, later that night with onset of severe abdominal 
pain, an emergency laparotomy was performed and the pregnancy was removed.

Four of the patients had IVF with 3 patients having a history of bilateral salpingectomy $[153,156,159]$, and the remaining patient with history of right salpingectomy and left hydrosalpinx with an occluded tube [154]. Four of the women required a blood transfusion [153-156]. All patients except 1 case [152] did not have a hemoperitoneum with free fluid in the pelvis despite sometimes massive bleeding in the retroperitoneal space. Fetal cardiac activity was noted in 2 of the cases [151,157] and there were no cases of maternal mortality.

\section{Abdominal Wall}

There were 7 cases of abdominal pregnancy with the primary implantation site being the abdominal wall [2, 161-166]. The average patient age was 25.6 with parity of 1.2 and gestational age of 12 weeks 4 days. All cases except 1 patient with implantation on left diaphragm, which was treated with laparoscopic hydrodistension [163], were treated with laparotomy. The average blood loss was 720 $\mathrm{ml}$ with 1 patient at 16 weeks receiving a blood transfusion [162] and postoperative methotrexate for placenta left in situ. Fetal cardiac activity was present in 2 patients $[165,166]$ with 1 maternal death [2].

\section{Other/Not Otherwise Specified}

There were 5 cases not specified $[24,167]$ with an average maternal age of 28.8, gestational age of 11 weeks 2 days and parity of 0.8 . The average blood loss was $530 \mathrm{ml}$. Two patients at 17 and 18 weeks, respectively, were treated with preoperative gel foam embolization of the hypogastric vessels followed by exploratory laparotomy [167]. Both patients also had elevated maternal serum AFP (4.8 and 6.5 MOM) and HCG (2.7 and 4.68 MOM). There were no maternal deaths.

\section{Intrauterine Device}

There were 18 cases ( $8 \%$ ) involving abdominal ectopic pregnancies with an IUD in situ $[20,22,24,28,36,56$, $104,113,123,126,135,137,139,147,148]$. Comparing those with and without IUD, those with an IUD were 2 years younger ( 27.6 vs. 29.7 ), had higher parity (1.75 vs. $1.3)$, were at a lower gestational age at the time of treatment (5 weeks 6 days vs. 10 weeks 0 days), and had higher estimated blood losses (2,390 vs. $1,450 \mathrm{ml})$ at the time of treatment. One possible explanation for the higher blood loss is that one third of the cases involved locations with known higher blood loss risk including the spleen and liver.

Early Abdominal Ectopic Pregnancies: A Systematic Review of the Literature

\section{Pathophysiology}

There are several theories about the pathophysiology of the ectopic abdominal pregnancy.

Berghella and Wolf [96] in their review of the pathophysiology of omental pregnancies refute primary implantation stating that the hypothesis that an ovum, to escape fimbria trapping, gets fertilized in the abdomen and implants on the omentum is unproven. Rather, they argue that omental pregnancy is secondary to a primary tubal or ovarian pregnancy that subsequently implants on the omentum. Cases reviewed up to the time of their review had failed to show neovascularization at the implantation site consistent with a primary omental pregnancy. However, Chang et al. [97] later reported a 5-week pregnancy implanted on the omentum with trophoblastic invasion, and Chopra et al. [98] reviewed a 6-week omental pregnancy with chorionic villi adjacent to the omental tissue with surrounding placental site reaction.

Paternoster and Santarossa [110] suggested that delayed ovulation occurring close to menses may reverse the fertilized ovum in its tubal course by retrograde menstrual flow. Cavanagh [168] postulated that fertilization may occur in the posterior cul-de-sac where sperm is known to accumulate and that an ovum could lay there due to dependent flow of peritoneal fluid. Paternoster and Santarossa [110] further postulated that the '... dynamics of intraperitoneal fluid flow may carry the zygote from the cul-de-sac to different bizarre intraperitoneal sites'.

Dmowski et al. [153] and Iwama et al. [156] hypothesized how the embryo arrives in the retroperitoneal space. As this case had ultrasound guidance of embryo transfer in a patient with a history of bilateral salpingectomy, it is argued that iatrogenic direct placement to be very unlikely considering length of catheter and the volume of transfer medium under ultrasound guidance. It also argues against intra-abdominal placement of embryos with spontaneous migration to the retroperitoneal space without peritoneal injury present. Therefore, the postulate is that the only remaining explanation for the occurrence of the retroperitoneal ectopic pregnancy would be spontaneous migration of the embryo from the uterus to the retroperitoneal space. It was considered, akin to uterine cancer, that the embryo could have traveled along the lymphatic channels to arrive at the retroperitoneal space. Hall et al. [155] concur with this theory with the proximity of lymph nodes adjacent to the ectopic with decidual changes as evidence. However, Iwama et al. [156] believe this to be less likely in the case presented as there was no

Gynecol Obstet Invest 2012;74:249-260 
histologic evidence of lymph tissue noted in the specimen. Rather, Iwama et al. [156] noted an adhesion to one of the tubal ends where salpingectomy took place and hypothesize that there could have been a fistulous track.

Ferland et al. [154] opine that for the retroperitoneal ectopic pregnancy found, it could have occurred through a left hydrosalpinx that was thought to be occluded or due to uterine perforation at time of IVF with implantation onto the peritoneum with trophoblastic invasion into the retroperitoneal space.

In the review by Arora [6] regarding ectopic pregnancy after total hysterectomy, it is believed that pregnancies that occur immediately after hysterectomy are due to a fertilization conception in the tubes being cut off from the uterus during surgery. Late pregnancies are thought to be due to a fistulous track between the vagina and peritoneum or prolapsed fallopian tube.

There were several pregnancies in patients who conceived via IVF including those with prior salpingectomies. Fisch et al. [59] believed that rather than uterine perforation occurring at the time of IVF, that a fistulous tract at the cornua was present.

Notwithstanding the existing theories of the pathophysiology of abdominal ectopic pregnancies, many investigators continue to use the Studdiford criteria for a primary abdominal pregnancy of (1) normal tubes and ovaries, (2) no evidence of uteroperitoneal fistula, (3) pregnancy related solely to the peritoneal surface, and (4) no evidence of secondary implantation following initial primary tubal nidation [1].

\section{Management}

Of the 225 cases, $90.1 \%$ were successfully managed by the initial treatment. Hepatic ectopic pregnancies required more treatment attempts (two or more treatments in 4 of the 13 cases) than ectopic pregnancies at other locations. Primary surgical management was performed in 208 cases $(87.8 \%)$ with the remaining being treated medically. Surgical treatment was more frequent because many of the patients presented initially with intra-abdominal bleeding. The identification of the abdominal ectopic pregnancy prior to bleeding has led more recently to primary medical treatment with $\mathrm{KCl}$ or methotrexate as an alternative to surgery. Surgery has been reserved for those patients who do not respond to medical management. We have also observed a trend in the later case reports of initially diagnosing the ectopics by laparoscopic examination and then treating them medically.

An IUD was present in approximately $8 \%$ of the women with abdominal ectopic pregnancies. Those women with early abdominal ectopic pregnancy and IUD in situ were more likely to have had more children and be younger which is consistent with IUD users in general. The earlier gestational age at which the ectopic was diagnosed may be partially explained by the increased suspicion for an ectopic pregnancy in current IUD users.

We observed that HCG levels did not correlate with the success or failure of medical management. In all these reported cases, $47 \%$ of women treated medically subsequently had to undergo an operative procedure. We were unable to discriminate any clinical parameters that predicted successful medical treatment of abdominal ectopic pregnancies using logistic regression for the following variables: maternal age, gestational age, location of ectopic, and $\beta$-HCG levels. A number of women who were initially treated medically had to subsequently be treated with multiple therapies. We believe the clinical decision about the treatment modality must be individualized for each patient.

\section{Placenta}

In the majority (210 of 225) of the case reports, the placentas were removed completely. Of the 16 cases with partial removal $[9,33,34,52,57,65,67,68,72,76,79,83$, $117,160,162]$, the most common postoperative complication was infection $[57,67,79,162]$. Methotrexate was given to 3 patients $[67,117,162]$. One patient had a pulmonary embolism [117]. The ability to completely remove the placenta is more than likely due to the earlier gestational age at the time of the treatment $(<20$ weeks $)$ and that most of these cases were treated surgically compared to advanced abdominal pregnancies. Traditionally, advanced abdominal pregnancies are treated by removing the pregnancy only and leaving the placenta in situ rather than removing it during the surgery [169].

\section{Maternal Mortality}

All 7 cases of maternal deaths in this review came from a longitudinal study by Atrash et al. [2] reviewing all deaths related to ectopic pregnancies from 1979 to 1982 in the USA with a maternal mortality rate of 5.1 deaths per 1,000 abdominal pregnancies. There were an estimated 2,147 abdominal pregnancies during the review period with a rate that is ninefold lower than has been reported in past decades. This lower maternal mortality is in part due to earlier diagnosis with ultrasound, use of laparoscopy, and routine HCG testing to confirm pregnancy. In our series, the mortality rate is 30 per 1,000 . The higher rate in this review is probably due to the inclusion of the mortality data from Atrash without having the 
data on those that did not die during the same period and the limitations of case reports. Additionally, there may have been overreporting of particularly vivid cases that led to death or it may represent a true measure of the mortality of this complication of pregnancy. For the practicing clinician, a high index of suspicion is always needed to ensure the timely diagnosis of an abdominal ectopic pregnancy. If the HCG level is rising and an intrauterine or ectopic pregnancy cannot be identified, an abdominal pregnancy should always be suspected until the location of the pregnancy is conclusively identified.

\section{Limitations of This Review}

A review that is primarily made up of case reports is limited. Only those cases published are reviewed which may represent the more complicated or rare cases of abdominal ectopic pregnancies. Because this condition is relatively rare, the true percentage of abdominal ectopic pregnancies stratified by location could only be derived by a sufficiently large cohort or case-control study, a series that included all abdominal ectopic pregnancies or large, well-characterized national health databases that would further clarify clinical associations for this population. In the absence of these studies, case reports and series are the only available sources to review. Secondly, this review was limited to pregnancies that were less than 20 weeks of gestation. The information about the gestational age of the abdominal pregnancy is based on the information and descriptions provided in the series and case reports. Most of those reports do not include information on how the gestational age was determined, and some of the pregnancies could have been greater than 20 weeks. Third, information about whether any locations were more or less difficult to diagnose, information of symptoms of the patients, how often ultrasound was performed and how fetal cardiac activity was determined would be very useful information to include in this review, however this review is limited to the information provided by the authors of the case reports and series.

\section{Conclusions}

Abdominal ectopic pregnancies are rare but dangerous complications of pregnancy. They are found in a myriad of locations and a number of treatment options have been reported. As abdominal ectopic pregnancies are diagnosed earlier in pregnancy ascribed to the use of HCG to diagnose the pregnancy and early ultrasounds to confirm pregnancy locations, abdominal ectopic pregnancies first diagnosed late in pregnancy will become very rare. Medical therapy is an option and may be successful in up to half of the cases. Unfortunately, there are no strong clinical predictors for successful medical therapy. The decision to use medical therapy must be individualized based on the distinctive characteristics of each case. Because the mortality from abdominal ectopic pregnancies may be higher than other ectopic pregnancies, the possibility must always be suspected and dealt with promptly by the astute clinician.

\section{Acknowledgement}

Donna G. Eastham, BA, Department of Obstetrics and Gynecology, University of Arkansas for Medical Sciences for her editing of the manuscript.

\section{References}

1 Studdiford WE: Primary peritoneal pregnancy. Am J Obstet Gynecol 1942;44:487491.

- Atrash HK, Friede A, Hogue CJ: Abdominal pregnancy in the United States: frequency and maternal mortality. Obstet Gynecol 1987;69:333-337.

-3 Allibone GW, Fagan CJ, Porter SC: The sonographic features of intra-abdominal pregnancy. J Clin Ultrasound 1981;9:383-387.

4 Angtuaco TL, Shah HR, Neal MR, Quirck JG: Ultrasound evaluation of abdominal pregnancy. Crit Rev Diagn Imaging 1994;35: $1-59$.
5 Apostolakis AP, Freeth D: Secondary abdominal pregnancy coexisting with intrauterine pregnancy. Panminerva Med 1977; 19:75-78.

-6 Arora VK: Abdominal pregnancy following total hysterectomy. Int Surg 1983;68:253255.

7 Brandt AL, Tolson D: Missed abdominal ectopic pregnancy. J Emerg Med 2006;30:171174.

$\checkmark 8$ Chatterjee SK, Chatterjee S, Chaudhuri P: Primary abdominal pregnancy complicated by intestinal obstruction. J Indian Med Assoc $1975 ; 64: 43-45$.
9 Cheng WF, Ho HN, Yang YS, Huang SC: Abdominal pregnancy after gonadotropin superovulation and intrauterine insemination: a case report. Am J Obstet Gynecol 1994;171: 1394-1395.

10 Cheung VY, Rosenthal DM: Abdominal pregnancy. J Minim Invasive Gynecol 2005;12:9.

11 Cooper JA: Early primary peritoneal pregnancy. J Obstet Gynaecol Br Commonw 1968;75:232-233.

12 Crespo R, Campillos JM, Villacampa A, Madani B, Navarro R, Tobajas JJ: Successful methotrexate treatment of an abdominal pregnancy in the pouch of Douglas. Clin Exp Obstet Gynecol 2008;35:289-290. 
13 Daw E, Colaco E: Primary peritoneal pregnancy on the anterior surface of the uterus. Br J Clin Pract 1978;32:205, 207.

14 DelRosario R, el-Roeiy A: Abdominal pregnancy on the bladder wall following embryo transfer with cryopreserved-thawed embryos: a case report. Fertil Steril 1996;66:839841.

-15 Durukan T, Urman B, Yarali H, Arikan U, Beykal O: An abdominal pregnancy 10 years after treatment for pelvic tuberculosis. Am J Obstet Gynecol 1990;163:594-595.

16 Garrett WJ, Crowe PH, Robinson DE: The interpretation of ultrasonic echograms in abdominal pregnancy. Aust NZ J Obstet Gynaecol 1969;9:26-28.

17 Geisler JP, Cline M, Eskew N Jr: Successful laparoscopic treatment of an abdominal pregnancy in the posterior cul-de-sac. Clin Exp Obstet Gynecol 2000;27:83-84

18 Gerli S, Rossetti D, Baiocchi G, Clerici G, Unfer V, Di Renzo GC: Early ultrasonographic diagnosis and laparoscopic treatment of abdominal pregnancy. Eur J Obstet Gynecol Reprod Biol 2004;113:103-105.

19 Giannopoulos T, Katesmark M: Ruptured tubal ectopic pregnancy with secondary implantation in the pouch of Douglas. J Obstet Gynaecol 2004;24:199-200.

-20 Ginath S, Malinger G, Golan A, Shahmurov M, Glezerman M: Successful laparoscopic treatment of a ruptured primary abdominal pregnancy. Fertil Steril 2000;74:601-602.

-21 Golbus MS, Sweet RL: Attempted prostaglandin abortion in two cases of abdominal pregnancy. Contraception 1976;13:385-388.

22 Goldman GA, Dicker D, Ovadia J: Primary abdominal pregnancy: can artificial abortion, endometriosis and IUD be etiological factors? Eur J Obstet Gynecol Reprod Biol 1988;27:139-143.

23 Graham D, Johnson TR Jr, Sanders RC: Sonographic findings in abdominal pregnancy. J Ultrasound Med 1982;1:71-74.

24 Hallatt JG, Grove JA: Abdominal pregnancy: a study of twenty-one consecutive cases. Am J Obstet Gynecol 1985;152:444-449.

-25 Hsieh CH, Hsu TY, Changchien CC: Abdominal pregnancy - report of two cases and review of literature. Changgeng Yi Xue Za Zhi 1994;17:268-275.

26 Jain S, Justus K, Bober S: Selective transvaginal embryo reduction in heterotopic pregnancy located intra-abdominally. J Obstet Gynaecol 2002;22:330.

-27 Johnson AG: Primary peritoneal pregnancy. Br Med J 1968;4:96-97.

28 Kasby C, Krins A: Primary peritoneal pregnancy in association with intrauterine contraceptive devices: two case reports. $\mathrm{Br} \mathrm{J} \mathrm{Ob-}$ stet Gynaecol 1978;85:794-795.

-29 Knopman JM, Talebian S, Keegan DA, Grifo JA: Heterotopic abdominal pregnancy following two-blastocyst embryo transfer. Fertil Steril 2007;88:1437.e13-e15.

- 30 Kun KY, Wong PY, Ho MW, Tai CM, Ng TK: Abdominal pregnancy presenting as a missed abortion at 16 weeks' gestation. Hong Kong Med J 2000;6:425-427.

- 31 Kwok A, Chia KK, Ford R, Lam A: Laparoscopic management of a case of abdominal ectopic pregnancy. Aust NZ J Obstet Gynaecol 2002;42:300-302.

32 Lawson JP, Myerson DA, Myerson PJ: Abdominal pregnancy. Br J Radiol 1976;49: 723-726.

33 Little KJ, Green MM: Abdominal gestation. J Emerg Med 1995;13:195-198.

- 34 Martin JN Jr, Sessums JK, Martin RW, Pryor JA, Morrison JC: Abdominal pregnancy: current concepts of management. Obstet Gynecol 1988;71:549-557.

- 35 McCullough AM: Abdominal pregnancy. Case report and review of the literature. J R Army Med Corps 1986;132:16-18.

-36 Muzsnai D, Hughes T, Price M, Bruksch L: Primary abdominal pregnancy associated with the IUD (two case reports). Eur J Obstet Gynecol Reprod Biol 1980;10:275-278.

37 Oliver R, Malik M, Coker A, Morris J: Management of extratubal and rare ectopic pregnancies: case series and review of current literature. Arch Gynecol Obstet 2007;276:125131.

38 Raynal P, Le Meaux JP, Lepercq J: Medical treatment of abdominal pregnancy. Eur J Obstet Gynecol Reprod Biol 2004;117:245-246.

39 Ringrose CA: The occurrence of non-tubal ectopic pregnancies in women with an intrauterine device. J Reprod Fertil 1979;55:373374.

40 Ross JA, Hacket E, Lawton F, Jurkovic D: Massive ascites due to abdominal pregnancy. Hum Reprod 1997;12:390-391.

41 Sacchi S, Vinci MO, Bellini F, Papotti M: Uncommon cases of ectopic pregnancy in a rural hospital. East Afr Med J 1986;63:813-817.

42 Shaw SW, Hsu JJ, Chueh HY, Han CM, Chen FC, Chang YL, Chao AS, Cheng PJ, Hsieh TT, Soong YK: Management of primary abdominal pregnancy: twelve years of experience in a medical centre. Acta Obstet Gynecol Scand 2007;86:1058-1062.

-43 Shin JS, Moon YJ, Kim SR, Kim KT, Moon H, Hwang YY: Primary peritoneal pregnancy implanted on the uterosacral ligament: a case report. J Korean Med Sci 2000;15:359-362.

44 Sinha RK: Primary abdominal pregnancy: review of the literature and a report of three cases. Med J Malaya 1970;25:108-112.

45 Tsudo T, Harada T, Yoshioka H, Terakawa N: Laparoscopic management of early primary abdominal pregnancy. Obstet Gynecol 1997; 90:687-688.

46 Veerareddy S, Sriemevan A, Cockburn JF, Overton TG: Non-surgical management of a mid-trimester abdominal pregnancy. BJOG 2004;111:281-283.

47 Vingnali M, Busacca M, Brigante C, Doldi N, Spagnolo D, Belloni C: Abdominal pregnancy as a result of gamete intrafallopian transfer (GIFT) and subsequent treatment with methotrexate: case report. Int J Fertil 1990; $35: 280-283$.
48 Zinger M, Rosenfeld D: Failed treatment of abdominal pregnancy with methotrexate. A case report. J Reprod Med 2001;46:392-394.

49 Abdalla HI, Ahuja KK, Morris N, Lynn J: Combined intra-abdominal and intrauterine pregnancies after gamete intrafallopian transfer. Lancet 1986;2:1153-1154.

50 Ahmed AH, Martin D, Onon TS: Secondary abdominal pregnancy associated with uterine fibroid. J Obstet Gynaecol 2005;25:206208

51 Balmaceda JP, Bernardini L, Asch RH, Stone SC: Early primary abdominal pregnancy after in vitro fertilization and embryo transfer. J Assist Reprod Genet 1993;10:317-320.

52 Bertrand G, Le Ray C, Simard-Emond L, Dubois J, Leduc L: Imaging in the management of abdominal pregnancy: a case report and review of the literature. J Obstet Gynaecol Can 2009;31:57-62.

53 Brennand JE, Morris AR, Greer IA: Prawn sandwiches, red herrings and abdominal pregnancy. Eur J Obstet Gynecol Reprod Biol 1997;74:13-14.

-54 Cordero DR, Adra A, Yasin S, O’Sullivan MJ: Intraligamentary pregnancy. Obstet Gynecol Surv 1994;49:206-209.

55 Clark JF, Guy RS: Abdominal pregnancy. Am J Obstet Gynecol 1966;96:511-520.

56 Dasari P, Devi S: Primary peritoneal pregnancy: a case report. J Obstet Gynaecol Res 2000;26:45-47.

57 Delke I, Veridiano NP, Tancer ML: Abdominal pregnancy: review of current management and addition of 10 cases. Obstet Gynecol 1982;60:200-204.

58 Deshpande N, Mathers A, Acharya U: Broad ligament twin pregnancy following in-vitro fertilization. Hum Reprod 1999;14:852-854.

-59 Fisch B, Peled Y, Kaplan B, Zehavi S, Neri A Abdominal pregnancy following in vitro fertilization in a patient with previous bilateral salpingectomy. Obstet Gynecol 1996;88: 642-643.

60 Friedrich EG Jr, Rankin CA Jr: Primary pelvic peritoneal pregnancy. Obstet Gynecol 1968;31:649-653.

61 Goh TH, Rahman SA: Primary peritoneal pregnancy implanted on the uterine fundus. Aust NZ J Obstet Gynaecol 1980;20:240-241.

-62 Goldman GA, Dicker D, Ovadia J: Primary abdominal pregnancy: can artificial abortion, endometriosis and IUD be etiological factors? Eur J Obstet Gynecol Reprod Biol 1988;27:139-143.

63 Hatada Y: The pedunculated type of primary peritoneal pregnancy implanted on the infundibulopelvic ligament. Obstet Gynecol 1993;82(suppl):693-695.

64 Kellett RJ: Primary abdominal (peritoneal) pregnancy. J Obstet Gynaecol Br Commonw 1973;80:1102-1105.

65 Kivikoski AI, Martin C, Weyman P, Picus D, Giudice L: Angiographic arterial embolization to control hemorrhage in abdominal pregnancy: a case report. Obstet Gynecol 1988;71:456-459. 
66 Kornblatt MB: Abdominal pregnancy following a total hysterectomy. Report of a case. Obstet Gynecol 1968;32:488-489.

-67 Loong EP, Kwok P: Management of early abdominal pregnancy. Br J Clin Pract 1988;42: 259-261.

68 Malian V, Lee JH: MR imaging and MR angiography of an abdominal pregnancy with placental infarction. AJR Am J Roentgenol 2001:177:1305-1306.

69 Morita Y, Tsutsumi O, Kuramochi K, Momoeda M, Yoshikawa H, Taketani Y: Successful laparoscopic management of primary abdominal pregnancy. Hum Reprod 1996; 11:2546-2547.

-70 Phupong V, Lertkhachonsuk R, Triratanachat S, Sueblinvong T: Pregnancy in the broad ligament. Arch Gynecol Obstet 2003; 268:233-235.

-71 Siow A, Chern B, Soong Y: Successful laparoscopic treatment of an abdominal pregnancy in the broad ligament. Singapore Med J 2004; 45:88-89.

-72 Strafford JC, Ragan WD: Abdominal pregnancy. Review of current management. Obstet Gynecol 1977;50:548-552.

73 Thomas JS, Willie JO, Clark JFJ: Primary peritoneal pregnancy: a case report. J Natl Med Assoc 1991;83:645-647.

74 Walton LA, Nikrui N: 'Salting out' an abdominal pregnancy. NY State J Med 1973;73:2782.

-75 Wiesenfeld HC, Guido RS: Intra-abdominal pregnancy after hysterectomy. N Engl J Med 2003;349:1534

76 Alexander MC, Horger EO 3rd: Early diagnosis of abdominal pregnancy by ultrasound. J Clin Ultrasound 1983;11:45-48.

-77 Ali CR, Fitzgerald C: Omental and peritoneal secondary trophoblastic implantation - an unusual complication after IVF. Reprod Biomed Online 2006;12:776-778.

78 Bennun M, van der Meulen J: A case of simultaneous abdominal and tubal pregnancy. East Afr Med J 1974;51:557-559.

79 Bergstrom R, Mueller G, Yankowitz J: A case illustrating the continued dilemmas in treating abdominal pregnancy and a potential explanation for the high rate of postsurgical febrile morbidity. Gynecol Obstet Invest 1998; 46:268-270.

80 Cobellis L, Stradella L, Messalli EM: Contribution to the choice of therapy in abdominal pregnancy. Panminerva Med 2000;42:159161.

81 Connor GF: Case of the month. Abdominal pregnancy. Crit Rev Comput Tomogr 2004; 45:11-16.

82 Dover RW, Powell MC: Management of a primary abdominal pregnancy. Am J Obstet Gynecol 1995;172:1603-1604.

-83 Levitt CA, Ingram JM: Abdominal pregnancy with complete ureteral obstruction: a case report. Am J Obstet Gynecol 1974;120:203-204.

-84 Meizner I, Glezerman M, Ben Harroch D, Leventhal H: Abdominal pregnancy following hysterectomy. Isr J Med Sci 1983;19:283285.
-85 Nakamura Y, Muso A, Tokuyama O, Sumi T, Yamamasu S, Ishiko O, Ogita S: Primary abdominal pregnancy associated with severe ovarian hyperstimulation syndrome. Arch Gynecol Obstet 2001;265:233-235.

86 Oehninger S, Kreiner D, Bass MJ, Rosenwaks Z: Abdominal pregnancy after in vitro fertilization and embryo transfer. $\mathrm{Ob}$ stet Gynecol 1988;72:499-502.

87 Qureshi RN, Chaudhuary N, Rizvi I, Afzal $\mathrm{M}$ : Feticide followed by successful removal of pregnancy products in early abdominal pregnancy. J Obstet Gynaecol (Tokyo 1995) 1995;21:13-16.

88 Saracoglu FO, Goksin E, Durukan T: Abdominal pregnancy following gonadotropin treatment. Am J Obstet Gynecol 1985; 153:804-805.

>89 Shumway JB, Greenspoon JS, Khouzami AN, Platt LD, Blakemore KJ: Amniotic fluid $\alpha$-fetoprotein and maternal serum $\alpha$-fetoprotein in abdominal pregnancies: correlation with extent and site of placental implantation and clinical implications. J Matern Fetal Med 1996;5:120-123.

$\$ 90$ Stovall TG, Elkins TE: Twin abdominal pregnancy. A case report. J Reprod Med 1985;30:784-786.

91 Strafford JC, Ragan WD: Abdominal pregnancy. Review of current management. Obstet Gynecol 1977;50:548-552.

92 Tromans PM, Coulson R, Lobb MO, Abdulla U: Abdominal pregnancy associated with extremely elevated serum $\alpha$-fetoprotein. Case report. Br J Obstet Gynaecol 1984;91: 296-298.

-93 Acker D, Jenson AB, Tenn GK: Abdominal pregnancy with intrauterine device in situ. Obstet Gynecol 1973;42:36-39.

$\$ 4$ Allen WL, Subba B, Yoong W, Fakokunde A: Chronic abdominal pregnancy following rupture from a bicornuate uterus. Arch Gynecol Obstet 2007;275:393-395.

95 Behjati S, Bamfo JE, Bates AW, Veerareddy S: A near miss: lessons from a case of omental pregnancy. J Obstet Gynaecol 2009;29: 559-560.

$>96$ Berghella V, Wolf SC: Does primary omental pregnancy exist? Gynecol Obstet Invest 1996;42:133-136.

$\checkmark 97$ Chang CK, Leu FJ, Teng SW: Primary omental pregnancy treated by laparoscopic surgery. Int J Gynaecol Obstet 2003;80: 325-326.

98 Chopra S, Keepanasseril A, Suri V, Gupta N: Primary omental pregnancy: case report and review of literature. Arch Gynecol Obstet 2009;279:441-442.

99 Chung MT, Lin YS, Wu MP, Huang KF: Laparoscopic surgery for omental pregnancy. J Am Assoc Gynecol Laparosc 2002;9: 84-86.
100 Da Silva BB, de Araujo EP, Cronemberger JN, dos Santos AR, Lopes-Costa PV: Primary twin omental pregnancy: report of a rare case and literature review. Fertil Steril 2008;90:2006.e13-5.

101 Esin S, Yildirim H, Tanzer F: Laparoscopic management of a primary omental pregnancy after clomiphene induction. Fertil Steril 2009;92:392.e1-3.

102 Friederich MA: Primary omental pregnancy. Two cases of primary peritoneal pregnancy. Obstet Gynecol 1968;31:104-109.

103 Hong JH, Shin JH, Song KJ, Lee HJ, Kim IS, Lee JK, Saw HS: Laparoscopic management of primary omental pregnancy. J Minim Invasive Gynecol 2008;15:640-641.

104 Hornemann A, Holl-Ulrich K, Finas D, Altgassen C, Diedrich K, Hornung D: Laparoscopic management of early primary omental pregnancy. Fertil Steril 2008;89:991.e9e11.

105 Karaer O, Ilkgül O, Oruç S: Primary omental pregnancy on the gastrocolic ligament. South Med J 2007;100:403-404.

106 Khalil A, Aslam N, Haider H, Creighton SM: Laparoscopic management of a case of unexpected omental pregnancy. J Obstet Gynaecol 2006;26:475-476.

107 Mousa HA, Thong J: Omental pregnancy in a woman taking the progestogen-only pill. Acta Obstet Gynecol Scand 2001;80:11391140.

108 Onan MA, Turp AB, Saltik A, Akyurek N, Taskiran C, Himmetoglu O: Primary omental pregnancy: case report. Hum Reprod 2005;20:807-809.

109 Ozdemir I, Demirci F, Yucel O, Alper M: Primary omental pregnancy presenting with hemorrhagic shock. A case report. Gynecol Obstet Invest 2003;55:116-118.

110 Paternoster DM, Santarossa C: Primary abdominal pregnancy. A case report. Minerva Ginecol 1999;51:251-253.

111 Shih CH: Primary abdominal pregnancy upon the omentum. Taiwan Yi Xue Hui Za Zhi 1969;68:453-457.

112 Weekes LR: Ectopic pregnancy: current clinical trends, a 15-year study. J Natl Med Assoc 1981;73:823-833.

113 Wong WC, Wong BP, Kun KY, Ng TK, Kwok SY, Lee CK: Primary omental ectopic pregnancy. J Obstet Gynaecol Res 2004;30: 226-229.

114 Yi KW, Yeo MK, Shin JH, Kim KA, Oh MJ, Lee JK, Hur JY, Saw HS: Laparoscopic management of early omental pregnancy detected by magnetic resonance imaging. J Minim Invasive Gynecol 2008;15:231-234.

115 Yildizhan R, Kurdoglu M, Kolusari A, Erten R: Primary omental pregnancy. Saudi Med J 2008;29:606-609.

$\checkmark 116$ Ben-Rafael Z, Dekel A, Lerner A, et al: Laparoscopic removal of an abdominal pregnancy adherent to the appendix after ovulation induction with human menopausal gonadotrophin. Hum Reprod 1995; 10: 1804-1805 
-117 Binder DS: Thirteen-week abdominal pregnancy after hysterectomy. J Emerg Med 2003;25:159-161.

118 Fisch B, Powsner E, Heller L, Goldman GA, Tadir Y, Wolloch J, Ovadia J: Heterotopic abdominal pregnancy following in-vitro fertilization/embryo transfer presenting as massive lower gastrointestinal bleeding. Hum Reprod 1995;10:681-682.

119 Ganeshselvi P, Cherian D, Champ S, Myerson N: Primary abdominal pregnancy implanted on the sigmoid colon. J Obstet Gynaecol 2003;23:667.

120 Goldman GA, Dicker D, Ovadia J: Primary abdominal pregnancy: can artificial abortion, endometriosis and IUD be etiological factors? Eur J Obstet Gynecol Reprod Biol 1988;27:139-143.

121 Goldstein AI, Walsh JW: Primary abdominal (peritoneal) pregnancy. J Okla State Med Assoc 1971;64:231-234.

122 Graham MF: First trimester abdominal preg- 141 nancy. J Clin Ultrasound 1977;5:321-322.

$\checkmark 123$ Mäkinen J: Histologically verified primary peritoneal pregnancy with implantation in the sigmoid mesenterium. Eur J Obstet Gynecol Reprod Biol 1986;22:171-174.

-124 Nama V, Gyampoh B, Karoshi M, McRae R, Opemuyi I: Secondary abdominal appendicular ectopic pregnancy. J Minim Invasive Gynecol 2007; 14:516-517.

-125 Barbosa Júnior Ade A, de Freitas LA, Mota MA: Primary pregnancy in the liver. A case report. Pathol Res Pract 1991;187:329-333.

-126 Børlum KG, Blom R: Primary hepatic pregnancy. Int J Gynaecol Obstet 1988;27:427429.

127 Chui AK, Lo KW, Choi PC, Sung MC, Lau JW: Primary hepatic pregnancy. ANZ Surg 2001;71:260-261.

128 Delabrousse E, Site O, Le Mouel A, Riethmuller D, Kastler B: Intrahepatic pregnancy: sonography and CT findings. AJR Am J Roentgenol 1999;173:1377-1378.

-129 Harris GJ, Al-Jurf AS, Yuh WT, Abu-Yousef MM: Intrahepatic pregnancy. A unique opportunity for evaluation with sonography, computed tomography, and magnetic resonance imaging. JAMA 1989;261:902-904.

-130 Hietala SO, Andersson M, Emdin SO: Ectopic pregnancy in the liver. Report of a case and angiographic findings. Acta Chir Scand 1983;149:633-635.

131 Kirby NG: Primary hepatic pregnancy. Br Med J 1969;1:296.

-132 Krause DW: Hepatic tumor or hepatic pregnancy? AJR Am J Roentgenol 1979;133: 355-356.

133 Mitchell RW, Teare AJ: Primary hepatic pregnancy. A case report and review. S Afr Med J 1984;65:220.

134 Nichols C, Koong D, Faulkner K, Thompson G: A hepatic ectopic pregnancy treated with direct methotrexate injection. Aust NZ J Obstet Gynaecol 1995;35:221-223.

135 Paulino-Netto A, Roselli A: Hepatic ectopic pregnancy: successful surgical treatment of a patient with hepatic pregnancy and acute hemorrhage. Mt Sinai J Med 1986;53:514517.

136 Shippey SH, Bhoola SM, Royek AB, Long ME: Diagnosis and management of hepatic ectopic pregnancy. Obstet Gynecol 2007; 109:544-546.

137 Veress B, Wallmander T: Primary hepatic pregnancy. Acta Obstet Gynecol Scand 1987;66:563-564.

138 Caruso V, Hall WH: Primary abdominal pregnancy in the spleen: a case report. $\mathrm{Pa}$ thology 1984;16:93-94.

139 Cormio G, Santamato S, Vimercati A, Selvaggi L: Primary splenic pregnancy. A case report. J Reprod Med 2003;48:479-481.

140 Gang G, Yudong Y, Zhang G: Successful laparoscopic management of early splenic pregnancy: case report and review of literature. J Minim Invasive Gynecol 2010;17: 794-797.

41 Huber DE, Martin SD, Orlay G: A case report of splenic pregnancy. Aust NZ J Surg 1984;54:81-82.

142 Kahn JA, Skjeldestad FE, Düring V, Sunde A, Molne K, Jørgensen OG: A spleen pregnancy. Acta Obstet Gynecol Scand 1989;68: 83-84.

143 Kalof AN, Fuller B, Harmon M: Splenic pregnancy: a case report and review of the literature. Arch Pathol Lab Med 2004; 128:e146-e148.

144 Kitade M, Takeuchi H, Kikuchi I, Shimanuki H, Kumakiri J, Kinoshita K: A case of simultaneous tubal-splenic pregnancy after assisted reproductive technology. Fertil Steril 2005;83:1042.

145 Larkin JK, Garcia DM, Paulson EL, Powers DW: Primary splenic pregnancy with intraperitoneal bleeding and shock: a case report. Iowa Med 1988;78:529-530.

146 Mankodi RC, Sankari K, Bhatt SM: Primary splenic pregnancy. Case report. Br J Obstet Gynaecol 1977;84:634-635.

147 Reddy KS, Modgill VK: Intraperitoneal bleeding due to primary splenic pregnancy. Br J Surg 1983;70:564.

148 Tantachamroon T, Songkrobhan S, Tuppasut NK: Primary splenic pregnancy. J Med Assoc Thai 1986;69:495-499.

149 Yackel DB, Panton ON, Martin DJ, Lee D: Splenic pregnancy - case report. Obstet Gynecol 1988;71:471-473.

150 Yagil Y, Beck-Razi N, Amit A, Kerner H, Gaitini D: Splenic pregnancy: the role of abdominal imaging. J Ultrasound Med 2007; 26:1629-1632.

151 Bae SU, Kim CN, Kim KH, Hwang IT, Choi YJ, Lee MK, Cho BS, Kang YJ, Park JS: Laparoscopic treatment of early retroperitoneal abdominal pregnancy implanted on inferior vena cava. Surg Laparosc Endosc Percutan Tech 2009;19:e156-e158.

152 Chang YL, Ko PC, Yen CF: Retroperitoneal abdominal pregnancy at left paracolic sulcus. J Minim Invasive Gynecol 2008;15: 660-661.
153 Dmowski WP, Rana N, Ding J, Wu WT: Retroperitoneal subpancreatic ectopic pregnancy following in vitro fertilization in a patient with previous bilateral salpingectomy: how did it get there? J Assist Reprod Genet 2002;19:90-93.

154 Ferland RJ, Chadwick DA, O’Brien JA, Granai CO 3rd: An ectopic pregnancy in the upper retroperitoneum following in vitro fertilization and embryo transfer. Obstet Gynecol 1991;78:544-546.

155 Hall JS, Harris M, Levy RC, Walrond ER: Retroperitoneal ectopic pregnancy. J Obstet Gynaecol Br Commonw 1973;80:9294.

156 Iwama H, Tsutsumi S, Igarashi H, Takahashi K, Nakahara K, Kurachi H: A case of retroperitoneal ectopic pregnancy following IVF-ET in a patient with previous bilateral salpingectomy. Am J Perinatol 2008;25: 33-36.

157 Lee JW, Sohn KM, Jung HS: Retroperitoneal ectopic pregnancy. AJR Am J Roentgenol 2005;184:1600-1601.

158 Mitra AG, LeQuire MH: Minimally invasive management of 14.5-week abdominal pregnancy without laparotomy: a novel approach using percutaneous sonographically guided feticide and systemic methotrexate. J Ultrasound Med 2003;22:709-714.

159 Reid F, Steel M: An exceptionally rare ectopic pregnancy. BJOG 2003;110:222-223.

160 Sotus PC: Retroperitoneal ectopic pregnancy: a case report. JAMA 1977;238:13631364.

161 Akhan O, Cekirge S, Senaati S, Besim A: Sonographic diagnosis of an abdominal ectopic pregnancy. AJR Am J Roentgenol 1990;155:197-198.

162 Attapattu JA, Menon S: Abdominal pregnancy. Int J Gynaecol Obstet 1993;43:51-55.

163 Dennert IM, van Dongen H, Jansen FW: Ectopic pregnancy: a heart beating case. J Minim Invasive Gynecol 2008;15:377-379.

164 Norenberg DD, Gundersen JH, Janis JF, Gundersen AL: Early pregnancy on the diaphragm with endometriosis. Obstet Gynecol 1977;49:620-622.

165 Ombelet W, van der Merwe JV: Combined extra- and intrauterine pregnancies. A report of 3 cases. S Afr Med J 1986;70:559560.

166 Zaki ZM: An unusual presentation of ectopic pregnancy. Ultrasound Obstet Gynecol 1998;11:456-458.

167 Bombard AT, Nakagawa S, Runowicz CD, Cohen BL, Mikhail MS, Nitowsky HM: Early detection of abdominal pregnancy by maternal serum AFP+ screening. Prenat Diagn 1994;14:1155-1157.

168 Cavanagh D: Primary peritoneal pregnancy. Am J Obstet Gynecol 1958;76:523-532.

169 Hreshchyshyn M, Bogen B, Loughran C: What is the actual present-day management of the placenta in late abdominal pregnancies? Am J Obstet Gynecol 1961;81: 302-317. 